\title{
Fish Welfare in Aquaculture
}

\section{Monique Mancuso*}

Institute for Coastal Marine Environment (IAMC) - National Research Council (CNR) -Section of Messina, Italy

\begin{abstract}
The global population is increasing and, in order to maintain at least the current level of per-capita consumption of aquatic foods, the aquaculture industry plays a key role. During these years a lot of studies were performed on negative effects on the fish welfare. At the moment the definition of welfare is a complex and controversial topic and regard different level that varies from a good health, behavior and absencence of pain.
\end{abstract}

\section{Keywords: Farmed fish; Welfare; Aquaculture}

\section{Introduction}

Fish and fishery products represent a very valuable source of protein and essential micronutrients for balanced nutrition and good health. The global population is increasing and, in order to maintain at least the current level of per-capita consumption of aquatic foods, the world will require an additional 23 million tonnes there of by 2020 . This additional supply will have to come from aquaculture [1]. In this contest the fish welfare is receiving increasing attention in the public and then in the world of research, industry and governments. In aquaculture, in fact, fish are often exposed to stress conditions, due to farming practices such as manipulation, selection, high stocking density, transportation, the conditions of pre-slaughter and slaughter methods.

\section{But ...What does it mean welfare?}

The definition itself is a complex and controversial topic!

The debate touch a number of complex scientific and ethical issues and constructive dialogue between groups with differing approaches to the topic requires mutual understanding from both perspectives [2]. In particularl there is the difficulty and contentious on the question of how welfare should be defined.

An animal's welfare may be deemed to be good if:

1) it can adapt to its environment and is in good health [3]

2) is able to lead a natural life, expressing the same kinds of behaviour as it would in the wild, taking a nature-based approach

3) Animal is free of negative experiences such as pain, fear and hunger and has access to positive experiences, such as social companionship.

These different definitions are not mutually exclusive, but reflect different facets of the complex phenomenon of animal welfare.

As discussed by Kaiser and Huntingford [4], there is still disagreement about which is the most appropriate definition to use when discussing fish welfare.

During the last decades the aquaculture industry increased together with the scientific knowledge about new technologies on farming but also several discussions on the potential negative effects linked to the welfare of cultured fish [5].

The definition of the welfare in fish is cause of debate and to date have not been yet established limits and measures, for this reason research into the effects of aquaculture procedures on welfare is crucial to produce data and recommendations for best practice and future legislation.
Both behavioral and physiological measures of welfare are necessary for correct interpretation and while there is a wealth of knowledge on the physiological consequences of many aquaculture practices it is now equally important for us to understand the behavioral responses to these practices and to relate them to fish welfare [5]

In the EU, Council Directive 98/58/EC lays down minimum standards for the protection of animals bred or kept for farming purposes, including fish. International organizations have also issued recommendations and guidelines concerning fish welfare. In 2005 the Council of Europe adopted a recommendation on the welfare of farmed fish and in 2008 the World Organization for Animal Health (OIE) adopted guiding principles for fish welfare. A number of codes of practice have also been adopted by industry that includes measures to safeguard fish welfare. In 2009 the AHAW Panel adopted an opinion on the general approach to fish welfare and on the aspects of stunning and killing methods for farmed fish [6].

The welfare is must be viewed as the interaction of multifactorial effects, in fact stocking density, diet, feeding technique, and management procedures all have strong effects on stress levels, subsequent stress tolerance, health, and the presence of aggressive behavior and consequentily these effects influenced strongly the welfare. And finally to avoiding unnecessary suffering on the part of farmed fish, to raise healthy animals in accordance with the welfare can only improve the quality of the product and therefore increase their commercial value.

In my opinion research should be conducted to reduce the stress in aquaculture practices together with behavioral and physiological response of the fish, is in fact necessary to adopt the guidelines and protocols that can be used all over the aquaculture sector.

\section{References}

1. FAO (2012) The State of World Fisheries and Aquaculture, FAO, France.

2. Huntingford FA, Adams CE, Braithwaite VA, Kadri S, Pottinger TG, Sandoe P \& Turnbull JF (2006) Current Issues in Fish Welfare. J Fish Biology 68: 332-372.

*Corresponding author: Monique Mancuso, Institute for Coastal Marine Environment (IAMC)-National Research Council (CNR)-Section of Messina, Spianata S. Raineri 86, 98122 Messina,Italy, Tel: 0906015438; E-mail: monique.mancuso@iamc.cnr.it

Received November 14, 2013; Accepted November 15, 2013; Published November 17, 2013

Citation: Mancuso M (2013) Fish Welfare in Aquaculture. J Aquac Res Development 4: e107 doi:10.4172/2155-9546.1000e107

Copyright: @ 2013 Mancuso M. This is an open-access article distributed under the terms of the Creative Commons Attribution License, which permits unrestricted use, distribution, and reproduction in any medium, provided the original author and source are credited. 
3. Huntingford FA, Kadri S (2009) Taking Account of Fish Welfare: Lessons from Aquaculture. J Fish Biol 75: 2862-2867

4. Kaiser MJ, Huntingford FA (2009) Introduction to Papers on Fish Welfare in Commercial Fisheries. J of Fish Biol 75: 2852-2854
5. Ashley PJ (2007) Fish Welfare: Current Issues in Aquaculture. Applied Anim Behav Science 104:199-235.

6. Branson EJ (2008) Fish Welfare. Branson Edition-Blackwell Publishing 1-316. 